\title{
Occurrence and prevalence of Cronobacter spp. in plant and animal derived food sources: a systematic review and meta-analysis
}

\author{
Norrakiah Abdullah Sani ${ }^{*}$ and Olumide A. Odeyemi ${ }^{1,2}$ (D)
}

\begin{abstract}
Cronobacter species are motile, non-spore forming, Gram negative emerging opportunistic pathogens mostly associated with bacteremia, meningitis, septicemia, brain abscesses and necrotizing enterocolitis in infected neonates, infants and immunocompromised adults. Members of the genus Cronobacter are previously associated with powdered infant formula although the main reservoir and routes of contamination are yet to be ascertained. This study therefore aim to summarize occurrence and prevalence of Cronobacter spp. from different food related sources. A retrospective systematic review and meta-analysis of peer reviewed primary studies reported between 2008 and 2014 for the occurrence and prevalence of Cronobacter spp. in animal and plant related sources was conducted using "Cronobacter isolation", "Cronobacter detection" and "Cronobacter enumeration" as search terms in the following databases: Web of Science (Science Direct) and ProQuest. Data extracted from the primary studies were then analyzed with meta-analysis techniques for effect rate and fixed effects was used to explore heterogeneity between the sources. Publication bias was evaluated using funnel plot. A total of 916 articles were retrieved from the data bases of which 28 articles met inclusion criteria. Cronobacter spp. could only be isolated from 103 (5.7\%) samples of animal related food while $123(19 \%)$ samples of plant related food samples harbors the bacteria. The result of this study shows that occurrence of Cronobacter was more prevalent in plant related sources with overall prevalence rate of $20.1 \%$ (95\% Cl 0.168-0.238) than animal originated sources with overall prevalence rate of $8 \%$ (95 \% Cl 0.066-0.096). High heterogeneity $\left(l^{2}=84\right)$ was observed mostly in plant related sources such as herbs, spices and vegetables compared to animal related sources $\left(P^{2}=82\right)$. It could be observed from this study that plant related sources serve as reservoir and contamination routes of Cronobacter spp.
\end{abstract}

Keywords: Prevalence, Reservoir, Contamination routes, Microbial food safety

\section{Background}

Cronobacter spp. are an emerging Gram-negative opportunistic pathogens mostly associated with neonatal infections such as infant meningitis, septicemia, bacteremia and necrotizing enterocolitis (NEC). They are formerly thought to be single species, called Enterobacter

\footnotetext{
*Correspondence: norrasani@ukm.edu.my

${ }^{1}$ Food Safety and Quality Research Group, School of Chemical Sciences and Food Technology, Faculty of Science and Technology, National University of Malaysia, Bangi, Malaysia

Full list of author information is available at the end of the article
}

sakazakii (Ghassem et al. 2011; Hunter and Bean 2013). As a genus, Cronobacter belongs to the family Enterobacteriaceae. Members of the genus are motile, flagellated, non-spore formers, facultative anaerobes. The current seven members of the genus are: C. sakazakii, C. turicensis, C. malonaticus, C. muytjensii, C. universalis, C. dublinensis and C. condimenti (Joseph et al. 2012). Initially, powdered infant formula was thought to be the major source of these pathogens since the product is not sterile, however, studies have shown that Cronobacter spp. are ubiquitous opportunistic pathogens (Pagotto and Farber

\section{Springer}


2009; Asato et al. 2013; Craven et al. 2010; Lehner et al. 2010; Mozrová et al. 2014; Mullane et al. 2008). They have been isolated from different sources ranging from animal related food sources like powdered infant formula, follow up formula and plant related food sources like vegetables, herbs and spices (Joseph et al. 2012; Althaus et al. 2012; El-Sharoud et al. 2009; Hochel et al. 2012; Molloy et al. 2009; O'Brien et al. 2009; Schmid et al. 2009). Due to the severity of infections of these pathogens and presence in different samples, various sources has been hypothesized as reservoir for Cronobacter in the past years. In a study conducted by Iversen and Forsythe (2003), the following plant related sources: wheat, rice, herbs and spices were concluded to be possible reservoir for these pathogens from which the bacteria are brought in contact to other food sources via cross contamination. Textile filters for exhaust air of milk powder-producing plant was also hypothesized by Jacobs et al. (2011) as reservoir. Additionally, Lou et al. (2014) in a recent study also concluded wheat flour as natural reservoir and/or transmission route for Cronobacter spp. It could therefore not be ascertained if plant or other source serve as reservoir and contamination routes of these pathogens.

Meta-analysis is a quantitative and summarizing statistical techniques aimed at extracting and combining scientific results from multiple primary studies investigating the same research question (Gonzales-Barron et al. 2013). According to Sutton et al. (2001), the primary aim of meta-analysis is production of precise estimate of the effect size of a particular treatment, with increased statistical power, rather than using a single study. Metaanalysis can also explain possible differences in the study outcomes of primary studies by coding study characteristics like research design features, data collection procedures, type of samples or even year (Hox and Leeuw 2003). Meta-analysis involves several steps. GonzalesBarron and Butler (2011a) suggested systematic review of literatures, data extraction of both qualitative and quantitative information from relevant primary studies, selection of effect size as described from each study, estimation of overall effect size of all the primary studies, assessment of heterogeneity of studies and presentation of meta-analysis using numerical (odd ratios, fixed effects size, $\mathrm{p}$ values, publication bias, meta regression, and random effect) and or graphical methods forest plot, funnel plot and others). In any scientific study, researchers can either perform experiment to generate data or utilize available data from previous study (primary study) without experimental work (den Besten and Zwietering 2012). Data from primary studies available in databases are usually used in meta-analysis. Until recently, only few meta-analytical studies have been conducted in food safety research as most meta-analysis are conducted in medical and social sciences. However, meta-analysis may be conducted in food safety research to proffer answers and solutions to mirage of research questions such as outbreak of food borne diseases, prevalence of microbial pathogens in foods, effect of pre- and post-harvest interventions, risk ranking of pathogens and consumer knowledge, attitude and practices (Xavier et al. 2014).

To the best of our knowledge, no meta-analysis has been conducted on estimation of overall occurrence, prevalence and detection of Cronobacter spp. in animal and plant related sources has been carried out in order to gain insight to source(s) of reservoir for these bacterial pathogens. This study therefore aim to systematically review and summarize primary studies describing occurrence and prevalence of Cronobacter spp. isolated from animal and plant food related sources with a view to identifying the natural reservoir and transmission routes of Cronobacter to other food sources.

\section{Methods}

This study was carried out following suggested steps of Gonzales-Barron and Butler (2011a). The steps consist of systematic review of literatures, data extraction of both qualitative and quantitative information from relevant primary studies, selection of effect size as described from each study, estimation of overall effect size of all the primary studies, assessment of heterogeneity of studies and meta-analysis representation of obtained result using numerical (odd ratios, fixed effects size, p values, publication bias, meta regression, and random effect) and or graphical methods forest plot, funnel plot and others).

\section{Literature search, selection and relevance screening}

A comprehensive literature search and systematic review of available primary studies aimed at producing summary of relevant, quality and initial findings from such studies. A problem statement describing the occurrence and prevalence of Cronobacter spp. in different samples to establish possible reservoir and routes of transmission of the pathogens was formulated to guide this study while the population considered in this study were various primary studies describing isolation of Cronobacter in plant and animal food related sources. Presence and absence of the bacteria under consideration were considered as possible outcome of each primary study. Following the establishment of problem statement, population and outcome, comprehensive search of electronic databases (ISI Web of science and ProQuest) was carried out using the following search algorithms: "Cronobacter isolation", "Cronobacter detection" and "Cronobacter enumeration".

Titles and abstracts of retrieved primary studies were examined for eligibility and relevance to the study. Thereafter, full text articles of eligible primary studies 
were obtained from the databases. Articles that are not freely available were obtained via pay per view service of the National University of Malaysia's library. Relevance of each article was screened using both inclusion and exclusion criteria. The inclusion criteria are isolation of Cronobacter from animal and plant originated food sources, description of isolation procedure, articles in English, full text and peer reviewed articles, number of samples and number of samples that are positive for presence of Cronobacter and total population are stated in the study while exclusion criteria are: review articles, detection of Cronobacter in artificially contaminated samples, non-peer reviewed articles such as thesis, opinion articles, non-food related sources of Cronobacter such as clinical samples and conference abstract due to lack of access to full articles. Articles were further checked for duplication using Endnote 5 software.

\section{Data extraction and assessment of quality}

Modified method of Xavier et al. (2014) was used to extract data from the primary selected studies. The number of samples examined for presence of the bacteria and number of positive outcome required to find out the event rate of the samples were obtained from data extracted from the following 28 primary studies ( $\mathrm{Li}$ et al. 2014; Jaradat et al. 2009; Baumgartner et al. 2009; Kandhai et al. 2010; Lee et al. 2012; Lou et al. 2014; Cetinkaya et al. 2013; Hochel et al. 2012; Terragno et al. 2009; Pan et al. 2014; El-Gamal et al. 2013; Chap et al. 2009; Wang et al. 2012). Characteristics of each primary study is summarized in Table 1.

\section{Statistical analysis of extracted data}

Statistical analyses was carried out using Comprehensive Meta-Analysis (CMA) software while $P$ values $<0.05$ were considered as statistically significant. Fixed effects model was used to analyze combined extracted data while variation of occurrence and prevalence of Cronobacter spp. between the primary studies was evaluated using heterogeneity $\left(I^{2}\right)$. Presence of bias in the publication was determined using funnel plots (odd of presence of Cronobacter spp. in the samples) of standard error. Forest plots were however used to estimate the event rate at $95 \%$ confidence intervals.

\section{Results}

\section{Literature search}

To the best of our knowledge, this study is the first metaanalytical study to be carried out with regard to these group of bacteria. The study was limited to 2008-2014 because many of the studies on isolation and characterization of Cronobacter were carried within these years.
Likewise, it was between these years that the taxonomy and grouping of the bacteria into genus was carried out. As it could be seen in Table 1, only few primary studies met the inclusion requirement of this meta-analysis. The primary studies considered in this meta-analysis described standard method for isolation and detection of Cronobacter from the samples.

The primary studies were broadly grouped into plant originated/derived food samples and animal originated/ derived food samples. In this study, systematic review of articles on primary studies was able to retrieve 916 articles (Web of Science -Science Direct $=633$ and ProQuest $=283$ respectively; 757 excluded based on relevance to study objectives while 159 articles were assessed for eligibility. Sixty-eight articles further excluded for inadequate information and 91 articles were eligible for qualitative review. Thereafter, 37 primary studies were excluded after deduplication. Twenty-eight (28) comprising of 12 studies on animal related sources of isolation of Cronobacter and 16 studies on plant related sources of isolation of Cronobacter were included in meta-analysis (Fig. 1). The six group of animal derived food samples in the 12 primary studies are powdered infant formula (1045 samples), follow formula (96 samples), powdered instant products (182 samples), milk powder (175 samples), pork (92 samples) and minced meat (222 samples) while the 10 group of plant derived food samples in the 16 primary studies are herbs (112 samples), spices (54 samples), cereals and cereal products (258 samples), fresh vegetables produce (47 samples), ready to eat foods (128), fruits (41 samples), wheat (13 samples), dry noodles (5 samples), rice flour (12 samples) and confessionary (42 samples) respectively hence, a total of 1812 of animal originated food samples and 644 plant related food samples were analyzed in all the primary studies. However, Cronobacter spp. could only be isolated from 103 (5.7 \%) samples of animal related food while 123 (19\%) samples of plant related food samples harbours the bacteria.

\section{Prevalence of Cronobacter spp. in plant and animal originated food samples}

The characteristics of the primary studies summarizing the type of samples, occurrence and prevalent rates of Cronobacter used in this systematic review and metaanalysis is outlined in Table 1. The result of this study shows that occurrence of Cronobacter was more prevalent in plant related sources with overall prevalence rate of $20.1 \%$ (95\% CI 0.168-0.238) as seen in the forest plot (Fig. 2) depicting forest plot of prevalence of Cronobacter spp. in plant originated food samples for fixed effects meta-analyses. Squares represent effect estimates of individual studies with their $95 \%$ confidence intervals of prevalence with size of squares proportional to the weight 
Table 1 Characteristics of primary research studies

\begin{tabular}{|c|c|c|c|c|}
\hline Study & Sample & No of sample & No of samples positive & References \\
\hline \multicolumn{5}{|c|}{ Plant derived food samples } \\
\hline Study 1 & Herbs & 22 & 1 & Li et al. (2014) \\
\hline Study 2 & Herbs & 67 & 26 & Jaradat et al. (2009) \\
\hline Study 3 & Herbs & 23 & 14 & Baumgartner et al. (2009) \\
\hline Study 4 & Spices & 28 & 1 & Kandhai et al. (2010) \\
\hline Study 5 & Spices & 26 & 7 & Baumgartner et al. (2009) \\
\hline Study 6 & Cereal and cereal products & 85 & 12 & Li et al. (2014) \\
\hline Study 7 & Cereal and cereal products & 123 & 6 & Kandhai et al. (2010) \\
\hline Study 8 & Cereal and cereal products & 50 & 8 & Lee et al. (2012) \\
\hline Study 9 & Fresh vegetable produce & 47 & 2 & Kandhai et al. (2010) \\
\hline Study 10 & Ready to eat food & 128 & 19 & Lee et al. (2012) \\
\hline Study 11 & Fruits & 41 & 3 & Lee et al. (2012) \\
\hline Study 12 & Wheat & 13 & 13 & Lou et al. (2014) \\
\hline Study 13 & Dry noodles & 5 & 5 & Lou et al. (2014) \\
\hline Study 14 & Rice flour & 7 & 2 & Lou et al. (2014) \\
\hline Study 15 & Rice flour & 12 & 4 & Cetinkaya et al. (2013) \\
\hline Study 16 & Confessionary & 42 & 3 & Baumgartner et al. (2009) \\
\hline \multicolumn{5}{|c|}{ Animal derived food samples } \\
\hline Study 17 & Powdered infant formula & 32 & 1 & Hochel et al. (2012) \\
\hline Study 18 & Powdered infant formula & 3 & 3 & Terragno et al. (2009) \\
\hline Study 19 & Powdered infant formula & 76 & 1 & Jaradat et al. (2009) \\
\hline Study 20 & Powdered infant formula & 399 & 49 & Pan et al. (2014) \\
\hline Study 21 & Powdered infant formula & 140 & 20 & El-Gamal et al. (2013) \\
\hline Study 22 & Follow up formula & 5 & 1 & Kandhai et al. (2010) \\
\hline Study 23 & Follow up formula & 91 & 3 & Chap et al. (2009) \\
\hline Study 24 & Powdered instant products & 182 & 1 & Kandhai et al. (2010) \\
\hline Study 25 & Milk powder & 175 & 7 & Kandhai et al. (2010) \\
\hline Study 26 & Pork & 92 & 2 & Wang et al. (2012) \\
\hline Study 27 & Minced meat & 222 & 7 & Kandhai et al. (2010) \\
\hline Study 28 & Powdered infant formula & 395 & 8 & Kandhai et al. (2010) \\
\hline
\end{tabular}

assigned to the study in the meta-analysis. The diamond represents the overall result and $95 \%$ confidence interval of the fixed-effects meta-analysis. The cumulative forest plot (Fig. 3), is the meta-analysis of all the primary studies in relation to each other. It displays results of mean prevalence rate of Cronobacter spp. from plant originated food samples by cumulatively adding one primary study at a time to another. In our study, overall prevalence rate of animal originated sources was $8 \%$ (95\% CI 0.066-0.096) indicated by the forest plot (Fig. 4) which depicts prevalence of Cronobacter spp. in animal originated food samples for fixed effects meta-analyses. Of all the 12 primary studies included in this study on animal originated food samples, only samples (3) analyzed in study 18 showed high prevalence rate of $87.5 \%$ (95\% CI 0.266-0.993) in comparison with the total samples (3) of powdered infant formula analyzed in the study.

\section{Publication bias among the primary studies}

Publication bias and quality of primary studies are limiting in meta-analysis (Noble 2006). Funnel plots are usually used to graphically assess publication bias in meta-analysis (Gonzales-Barron and Butler 2011b; Soon et al. 2012). This is obtained by plotting standard error against prevalence rate. In our study, publication bias could be observed among the primary studies due to asymmetric nature of the plots. Solid vertical line in the funnel plots represents the summary of prevalence rate derived from fixed-effect meta-analysis while the diagonal lines represent $95 \%$ confidence interval. The cumulative forest plot (Fig. 5) of all the primary studies shows the mean prevalence rate of Cronobacter spp. from animal originated food samples by cumulatively adding one primary study at a time to another. Additionally, there is need for more studies on animal related sources of Cronobacter and 


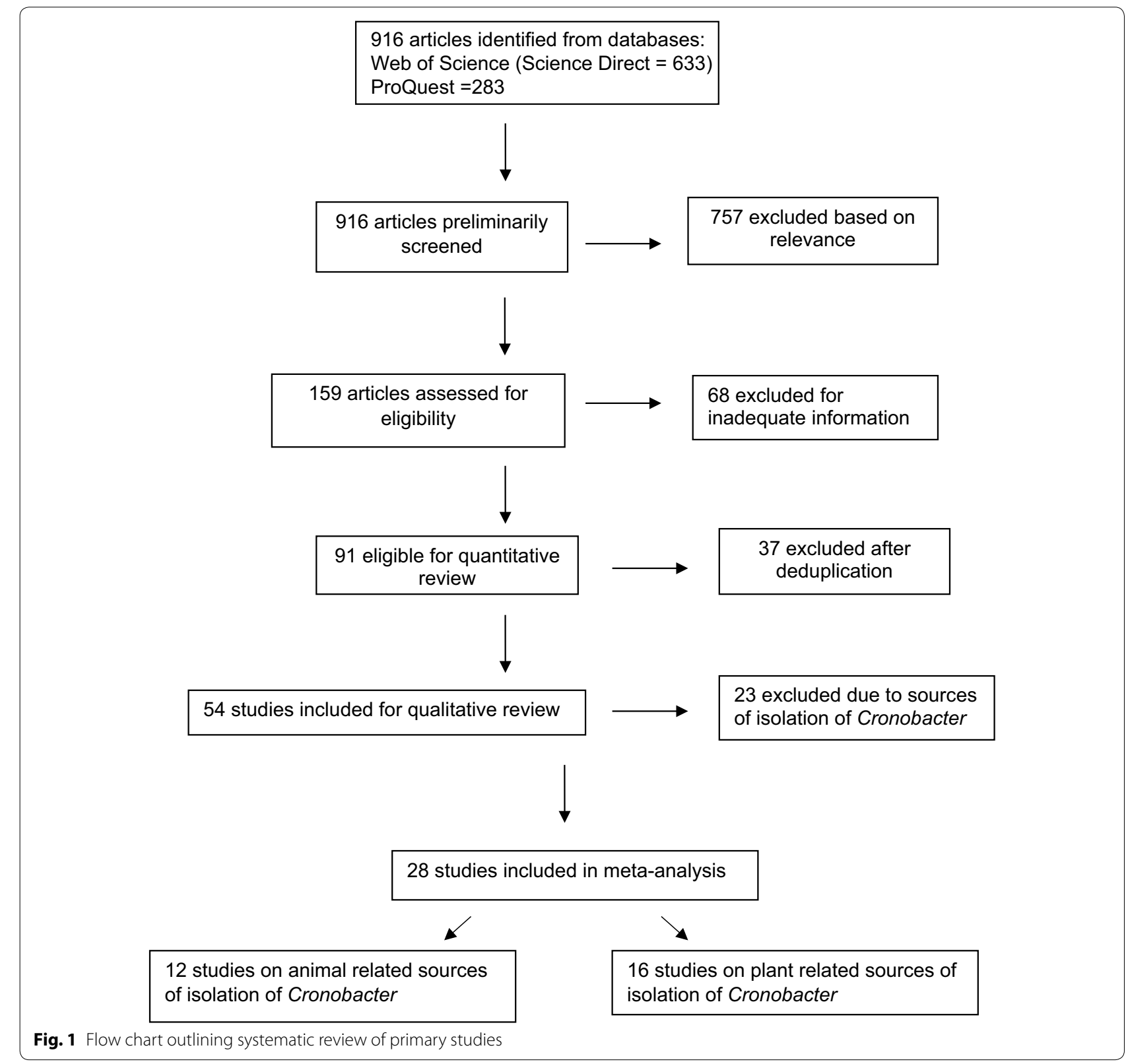

the results of the research should be communicated in scientific publications. Some of the factors that can may possibly contribute to asymmetric funnel shape includes insufficient sample size, under reported primary research (Gonzales-Barron and Butler 2011b).

In the funnel plots of prevalence of Cronobacter spp. in plant originated food samples (Fig. 6), most of the primary studies cluster at the top away from the effect size and toward the confidence interval at the left side of the plot between standard error 0.5 and 1. Likewise in Fig. 7, majority of the primary studies cluster at the top away from the effect size and toward the confidence interval at the left side of the plot between standard error 0.5 and 1. Publication bias among studies in Fig. 7 is higher than Fig. 6. More so, high heterogeneity $\left(I^{2}=84\right)$ was observed mostly in plant related sources such as herbs, spices and vegetables compared to animal related sources $\left(I^{2}=82\right)$ which correlates with the fact that more plant related food sources were included in this study than animal related samples.

\section{Discussion}

Over the years, the number of studies on Cronobacter have increased. Despite this increase, the reservoir and 


\begin{tabular}{lrrrrr} 
Study name & \multicolumn{5}{c}{ Statistics for each study } \\
\hline \multicolumn{7}{c}{$\begin{array}{c}\text { Event } \\
\text { rate }\end{array}$} & $\begin{array}{l}\text { Lower } \\
\text { limit }\end{array}$ & \multicolumn{3}{c}{ Upper } \\
limit & Z-Value & p-Value \\
Study 1 & 0.045 & 0.006 & 0.261 & -2.975 & 0.003 \\
Study 2 & 0.388 & 0.280 & 0.509 & -1.817 & 0.069 \\
Study 3 & 0.609 & 0.402 & 0.782 & 1.034 & 0.301 \\
Study 4 & 0.036 & 0.005 & 0.214 & -3.236 & 0.001 \\
Study 5 & 0.269 & 0.134 & 0.467 & -2.258 & 0.024 \\
Study 6 & 0.141 & 0.082 & 0.232 & -5.796 & 0.000 \\
Study 7 & 0.049 & 0.022 & 0.104 & -7.096 & 0.000 \\
Study 8 & 0.160 & 0.082 & 0.289 & -4.299 & 0.000 \\
Study 9 & 0.074 & 0.019 & 0.252 & -3.437 & 0.001 \\
Study 10 & 0.148 & 0.097 & 0.221 & -7.027 & 0.000 \\
Study 11 & 0.073 & 0.024 & 0.204 & -4.234 & 0.000 \\
Study 12 & 0.964 & 0.616 & 0.998 & 2.289 & 0.022 \\
Study 13 & 0.917 & 0.378 & 0.995 & 1.623 & 0.105 \\
Study 14 & 0.286 & 0.072 & 0.673 & -1.095 & 0.273 \\
Study 15 & 0.333 & 0.131 & 0.624 & -1.132 & 0.258 \\
Study 16 & 0.071 & 0.023 & 0.199 & -4.281 & 0.000 \\
& 0.201 & 0.168 & 0.238 & -12.352 & 0.000
\end{tabular}

Event rate and $95 \% \mathrm{Cl}$

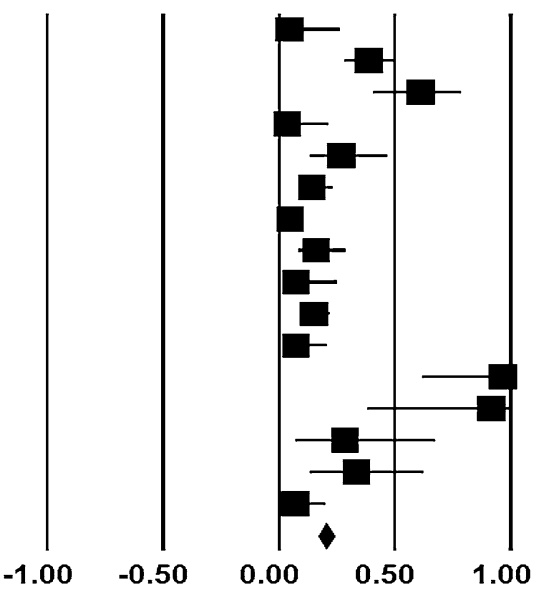

Fig. 2 Forest plots of prevalence of Cronobacter spp. in plant originated food samples for fixed effects meta-analyses (squares represent effect estimates of individual studies with their $95 \%$ confidence intervals of prevalence with size of squares proportional to the weight assigned to the study in the meta-analysis). The diamond represents the overall result and $95 \%$ confidence interval of the fixed-effects meta-analysis

\begin{tabular}{|c|c|c|c|c|c|}
\hline \multicolumn{2}{|c|}{ Study name } & \multicolumn{4}{|c|}{ Cumulative statistics } \\
\hline & Point & $\begin{array}{c}\text { Lower } \\
\text { limit }\end{array}$ & $\begin{array}{c}\text { Upper } \\
\text { limit }\end{array}$ & Z-Value & p-Value \\
\hline Study 1 & 0.045 & 0.006 & 0.261 & -2.975 & 0.003 \\
\hline Study 2 & & 0.254 & 0.469 & -2.472 & 0.013 \\
\hline Study 3 & 0.414 & 0.318 & 0.517 & -1.636 & 0.102 \\
\hline Study 4 & 0.385 & 0.294 & 0.484 & -2.260 & 0.024 \\
\hline Study 5 & 0.363 & 0.283 & 0.4 & -3.005 & 0.003 \\
\hline Study 6 & 0.290 & 0.2 & 0.3 & -5.564 & 0.000 \\
\hline Study 7 & 0.23 & 0.1 & 0.296 & -7.738 & 0.000 \\
\hline Study 8 & 0.227 & 0.1 & 0.278 & -8.770 & \\
\hline Study 9 & 0.219 & 0.1 & 0.268 & -9.257 & 00 \\
\hline Study 10 & 0.201 & 0.165 & 0.241 & -11.501 & 0.000 \\
\hline Study 11 & 0.194 & 0.160 & 0.232 & -12 & 0.000 \\
\hline Study 12 & 0.198 & 0.164 & 0.238 & -11.882 & 0.000 \\
\hline Study 13 & 0.202 & 0.168 & 0.242 & -11.716 & 0.0 \\
\hline Study 14 & 0.204 & 0.169 & 0.243 & -11.754 & 0.000 \\
\hline Study 15 & 0.207 & 0.173 & 0.247 & -11.760 & 0.000 \\
\hline Study 16 & 0.201 & 0.168 & 0.238 & -12.352 & 0.000 \\
\hline & 0.201 & 0.168 & 0.238 & -12.352 & 0.000 \\
\hline
\end{tabular}

\section{Cumulative event rate $(95 \% \mathrm{Cl})$}

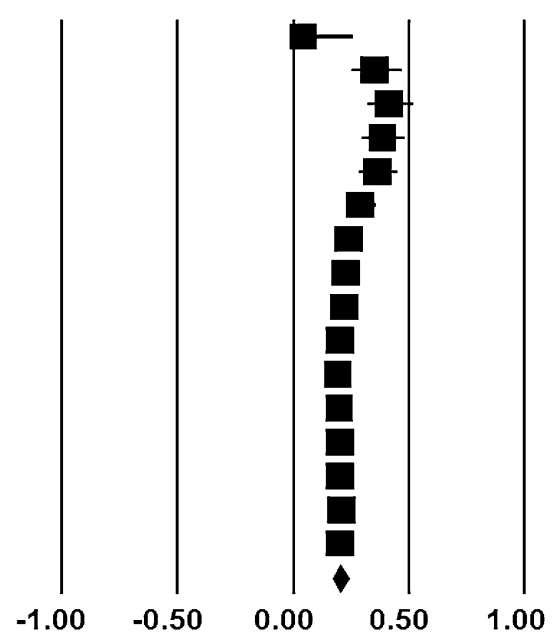

Fig. 3 Cumulative meta-analysis of prevalence of Cronobacter spp. in plant originated food samples

routes of contamination of this bacteria is yet to be unanimously agreed upon by researchers. There is there need to conduct meta-analysis which quantitatively combine results of available primary studies with a view to identify the reservoir and possible contamination routes of Cronobacter. It is also used to explore any form of bias 


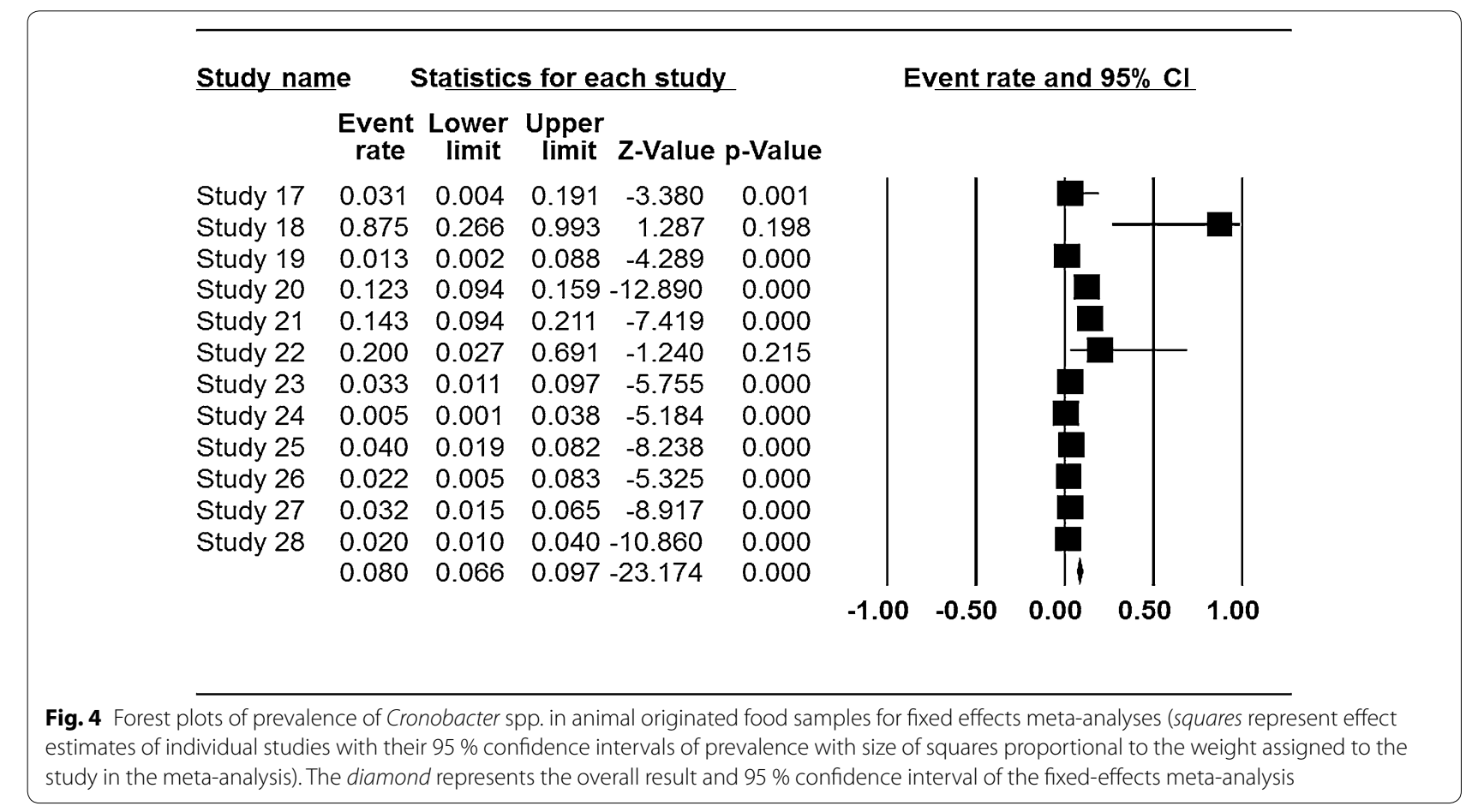

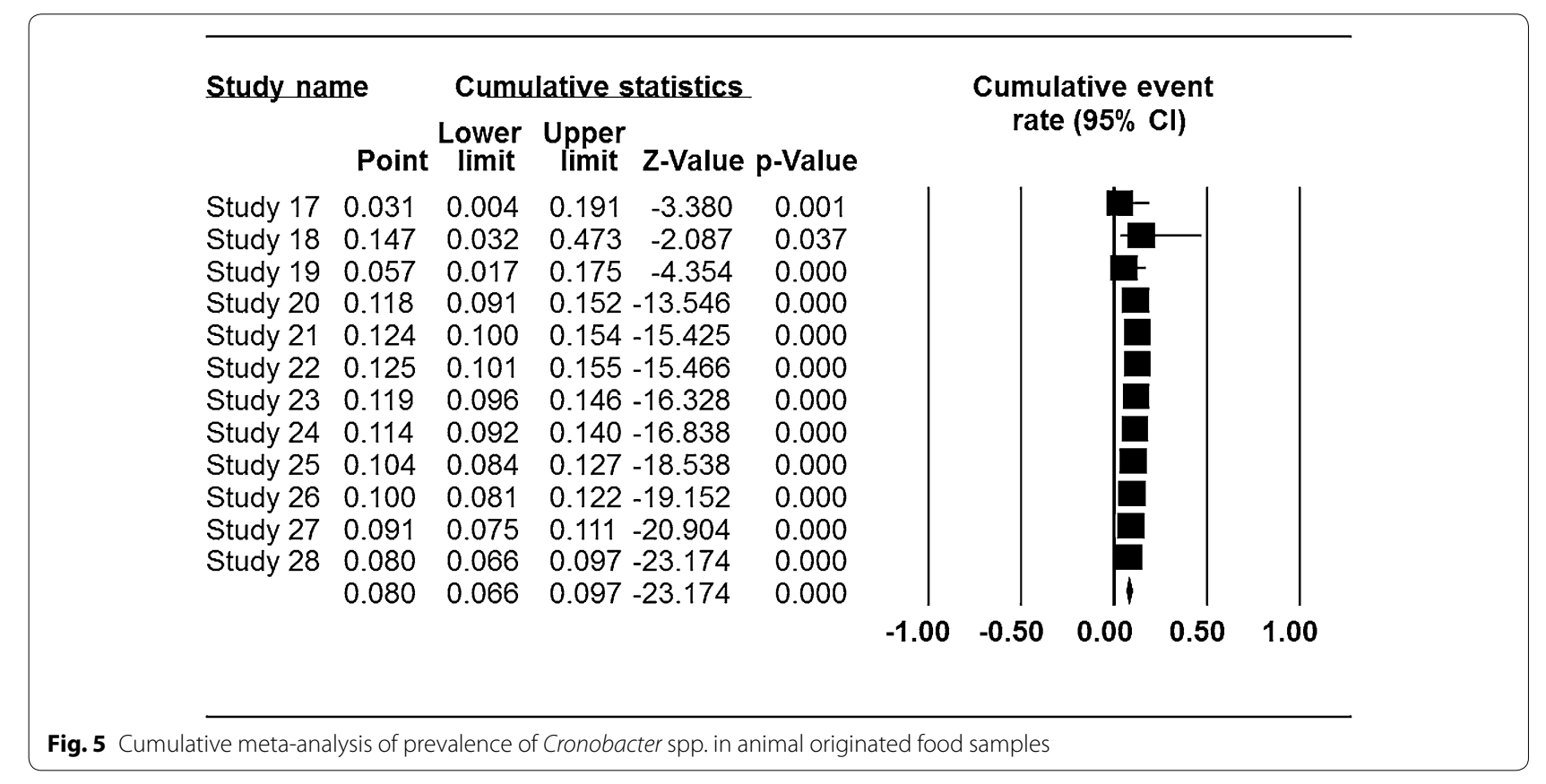

in the samples by cumulatively adding studies according to sample the number of samples that are positive for the presence of Cronobacter in relation to the sample size of each primary study. Although both summary effect forest plot and cumulative forest plot of primary studies on plant originated food look similar, in terms of the point estimate and confidence interval, however, it could be noted that cumulative forest plot showed persistence in the pattern of the obtained values. This was similar to the pattern of results obtained by Soon et al. (2012) in their study of meta-analysis of food handlers' knowledge and attitudes towards food safety. 


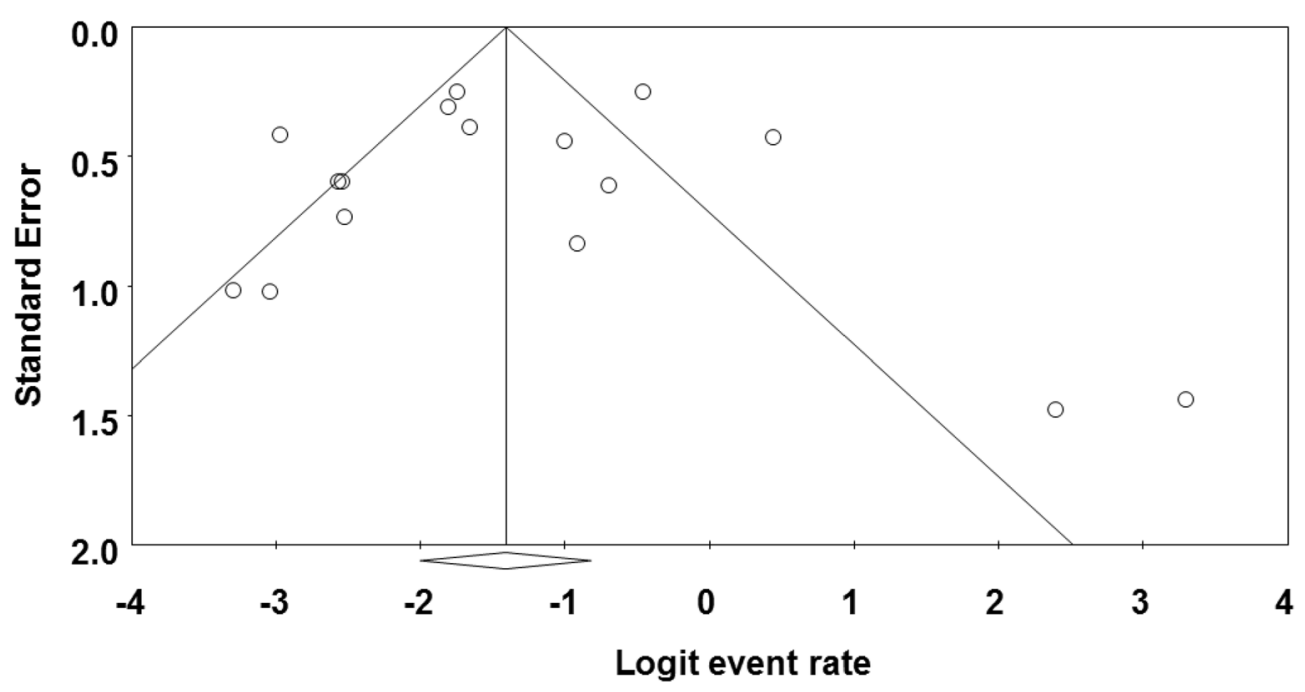

Fig. 6 Funnel plot of prevalence of Cronobacter spp. in plant originated food samples. Solid vertical line represents the summary prevalence rate derived from fixed-effect meta-analysis while the diagonal lines represent $95 \%$ confidence interval

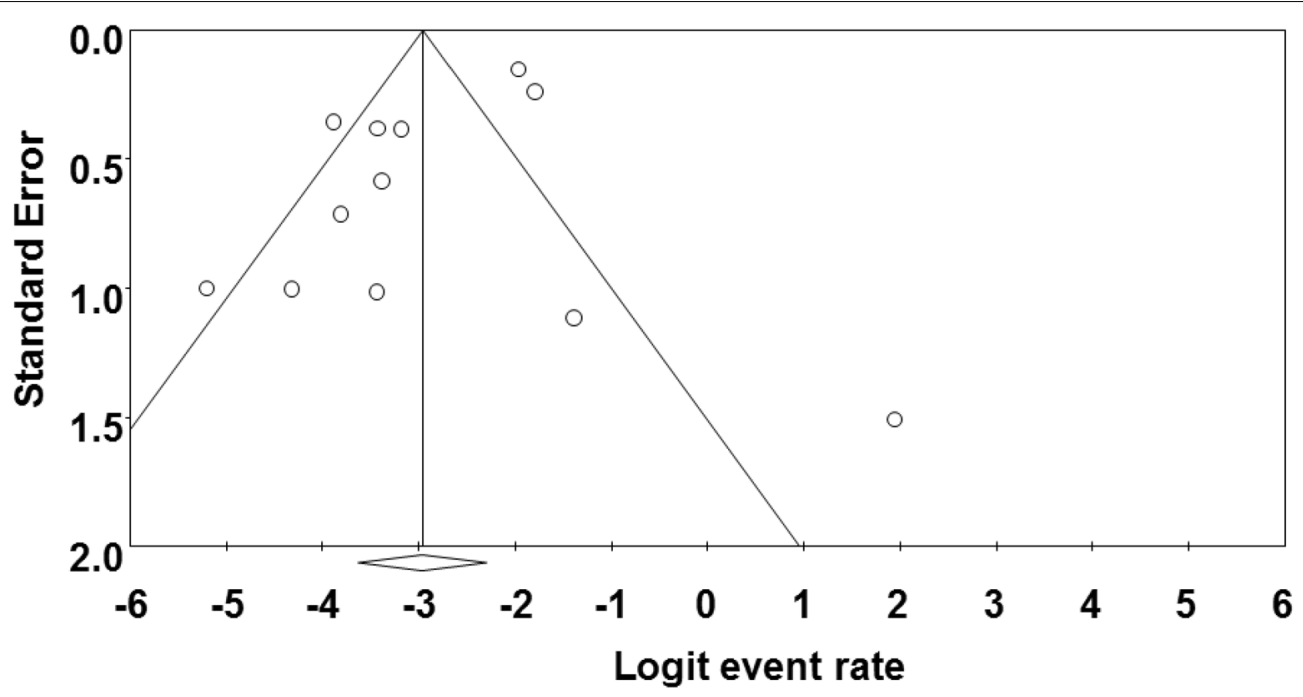

Fig. 7 Funnel plot of prevalence of Cronobacter spp. in animal originated food samples. Solid vertical line represents the summary prevalence rate derived from fixed-effect meta-analysis while the diagonal lines represent $95 \%$ confidence interval

Variance in occurrence of Cronobacter between primary studies was observed in our study. The bacteria was more prevalent in samples analyzed in primary study 12 than others with prevalence rate of $96.4 \%$ (95\% CI 0.6160.998). This was as result of isolation of Cronobacter from all the 13 samples of wheat investigated in the study. Similarly, study 13 has high prevalence rate 91.7 \% (95\% CI 0.378-0.995) as result of isolation of Cronobacter from all 5 samples of dry noodles examined in the primary study. It could be observed that both samples were analyzed in the same primary studies. There could possibly be some form of cross contamination during processing of the samples. However, this was not stated in the study. Contamination of food products constitute one of the major transmission routes for opportunistic foodborne pathogen (Lou et al. 2014). Studies have shown that Cronobacter could survive in food samples with low activity water. According to Osaili and Forsythe (2009), Cronobacter has various survival mechanisms including resistance to desiccation and osmotic stresses (Osaili and Forsythe 2009). These survival mechanisms will enable the persistence of the bacteria in the environment and dry food samples. 
The least plant derived food samples contaminated with Cronobacter is the study involving spices. Spices are also dry plant derived ingredients. However, considering the prevalence rate to other studies, it showed prevalent rate of $3.6 \%$ (95 \% CI 0.005-0.214).

Powdered infant formula has been initially thought to be the main source of Cronobacter due to the fact the products are not sterile however our study has shown that other sources could serve as reservoir and transmission routes to this opportunistic pathogens. Study 24 involving analysis of powdered instant products has the least prevalence rate of $5 \%$ (95\% CI 0.001-0.038). It will be noted likewise that the results of study 18 and study 22 are statistically insignificant with $\mathrm{p}$ values $>0.005$. Both summary effect forest plot and cumulative forest plot of primary studies on animal originated food look similar, in terms of the point estimate and confidence interval, only study 18 shows large confidence interval while the remaining studies exhibited similar pattern down the study. Our current meta-analysis implies that more studies involving isolation of Cronobacter spp., from spices and other plant related sources need to be carried out.

\section{Conclusion}

This current study is the first systematic review and meta-analysis to be conducted on occurrence and prevalence of Cronobacter in various samples. This outcome of this study supported some individual study stipulating that plant related food sources such as wheat, herbs, spices and flour could be potential reservoir and routes of contamination of Cronobacter. Although more animal related samples were analyzed than samples from plant related sources by the primary research studies included in the meta-analysis, occurrence of Cronobacter was more prevalent in plant related samples. Meta-analysis is without limitations. In our study, one of the possible limitation encountered is that only studies reported in English language were used. There could be possibility that positive results involving isolation of Cronobacter from animal related sources are reported. This correlates with the publication bias observed in the study which involve publication of study with significant results. Additionally, primary research studies involving clinical samples were not included in this study. It could be observed from this study that plant related sources serve as reservoir and contamination routes of Cronobacter spp., however more meta - analytical study to investigate prevalence of Cronobacter spp., among various samples within animal and plant sources.

\section{Authors' contributions}

All authors were involved in this study. This study is part of project conceived by NAS. OAO designed the analysis, collected the data, and performed the statistical analysis. Both authors read and approved the final manuscript.

\section{Author details}

${ }^{1}$ Food Safety and Quality Research Group, School of Chemical Sciences and Food Technology, Faculty of Science and Technology, National University of Malaysia, Bangi, Malaysia. ${ }^{2}$ Ecology and Biodiversity, Institute for Marine and Antarctic Studies, University of Tasmania, Hobart, Australia.

\section{Acknowledgements}

This research is supported by research grant DIP- 2014-007.

Compliance with ethical guidelines

\section{Competing interests}

The authors declare that they have no competing interests.

Received: 31 July 2015 Accepted: 9 September 2015

Published online: 24 September 2015

\section{References}

Althaus D, Hofer E, Corti S, Julmi A, Stephan R (2012) Bacteriological survey of ready-to-eat lettuce, fresh-cut fruit, and sprouts collected from the Swiss market. J Food Prot 75(7):1338-1341

Asato VC, Vilches VE, Pineda MG, Casanueva E, Cane A, Moroni MP, Brengi SP, Pichel MG (2013) First clinical isolates of Cronobacter spp. (Enterobacter sakazakii) in Argentina: characterization and subtyping by pulsed-field gel electrophoresis. J Microbiol Argentina 45(3):160-164

Baumgartner A, Grand M, Liniger M, Iversen C (2009) Detection and frequency of Cronobacter spp. (Enterobacter sakazakii) in different categories of ready-to-eat foods other than infant formula. Int J Food Microbiol 136:89-192

Cetinkaya E, Joseph S, Ayhan K, Forsythe SJ (2013) Comparison of methods for the microbiological identification and profiling of Cronobacter species from ingredients used in the preparation of infant formula. Mol Cell Probes 27:60-64. doi:10.1016/.mcp.2012.10.003

Chap J, Jackson P, Siqueira R, Gaspar N, Quintas C, Park J, Osaili T, Shaker R, Jaradat Z, Hartantyo S (2009) International survey of Cronobacter sakazakii and other Cronobacter spp. in follow up formulas and infant foods. Int J Food Microbiol 136(2):185-188

Craven HM, McAuley CM, Duffy LL, Fegan N (2010) Distribution, prevalence and persistence of Cronobacter (Enterobacter sakazakii) in the nonprocessing and processing environments of five milk powder factories. J Appl Microbiol 109(3):1044-1052

den Besten HM, Zwietering MH (2012) Meta-analysis for quantitative microbiological risk assessments and benchmarking data. Trends Food Sci Technol 25:34-39

El-Gamal M, El Dairouty R, Okda A, Salah SH, El-Shamy S (2013) Incidence and interrelation of Cronobacter sakazakii and other foodborne bacteria in some milk products and infant formula milks in Cairo and Giza area. World Appl Sci J 26(9):1129-1141

El-Sharoud WM, O'Brien S, Negredo C, Iversen C, Fanning S, Healy B (2009) Characterization of Cronobacter recovered from dried milk and related products. BMC Microbiol 9(1):24

Ghassem M, Babji A, Forsythe S, Norrakiah A (2011) Growth and survival of Cronobacter species as measured by media performance. Int Food Res J 18:367-372

Gonzales-Barron U, Butler F (2011a) The use of meta-analytical tools in risk assessment for food safety. Food Microbiol 28:823-827

Gonzales-Barron U, Butler F (2011 b) Characterisation of within-batch and between-batch variability in microbial counts in foods using Poissongamma and Poisson-lognormal regression models. Food Control 22(8):1268-1278

Gonzales-Barron U, Cadavez V, Sheridan JJ, Butler F (2013) Modelling the effect of chilling on the occurrence of Salmonella on pig carcasses at study, abattoir and batch levels by meta-analysis. Int J Food Microbiol 163:101-113

Hochel I, Rủžičková H, Krásný L, Demnerová K (2012) Occurrence of Cronobacter spp. in retail foods. J Appl Microbiol 112(6):1257-1265 
Hox JJ, Leeuw ED (2003) Multilevel models for meta-analysis. In: Reise SP, Duan N (eds) Multilevel modeling: methodological advances, issues, and applications. Erlbaum Associates, Mahwah, NJ, pp 90-111

Hunter C, Bean J (2013) Cronobacter: an emerging opportunistic pathogen associated with neonatal meningitis, sepsis and necrotizing enterocolitis. J Perinatol 33:581-585

Iversen C, Forsythe S (2003) Risk profile of Enterobacter sakazakii, an emergent pathogen associated with infant milk formula. Trends Food Sci Technol 14(11):443-454

Jacobs C, Braun P, Hammer P (2011) Reservoir and routes of transmission of Enterobacter sakazakii (Cronobacter spp.) in a milk powder-producing plant. J Dairy Sci 94:3801-3810

Jaradat Z, Ababneh Q, Saadoun I, Samara N, Rashdan A (2009) Isolation of Cronobacter spp. (formerly Enterobacter sakazakii) from infant food, herbs and environmental samples and the subsequent identification and confirmation of the isolates using biochemical, chromogenic assays, PCR and 16S rRNA sequencing. BMC Microbiol 9:225-235

Joseph S, Sonbol H, Hariri S, Desai P, McClelland M, Forsythe SJ (2012) Diversity of the Cronobacter genus as revealed by multilocus sequence typing. J Clin Microbiol 50:3031-3039. doi:10.1128/jcm.00905-12

Kandhai MC, Heuvelink AE, Reij MW, Beumer RR, Dijk R, van Tilburg JJH et al (2010) A study into the occurrence of Cronobacter spp. in The Netherlands between 2001 and 2005. Food Control 21:1127-1136

Lee Y-D, Park J-H, Chang H (2012) Detection, antibiotic susceptibility and biofilm formation of Cronobacter spp. from various foods in Korea. Food Control 24(1):225-230

Lehner A, Fricker-Feer C, Gschwend K, Stephan R (2010) Identification of Enterobacteriaceae and Cronobacter spp. in raw milk, milk concentrate and milk powder: prevalence and genotyping. J Food Safety Food Qual 5(1):22-26

Li Y, Chen Q, Zhao J, Jiang H, Lu F, Bie X, Lu Z (2014) Isolation, identification and antimicrobial resistance of Cronobacter spp. isolated from various foods in China. Food Control 37:109-114. doi:10.1016/j.foodcont.2013.09.017

Lou X, Si G, Yu H, Qi J, Liu T, Fang Z (2014) Possible reservoir and routes of transmission of Cronobacter (Enterobacter sakazakii) via wheat flour. Food Control 43:258-262. doi:10.1016/j.foodcont.2014.03.029

Molloy C, Cagney C, O'Brien S, Iversen C, Fanning S, Duffy G (2009) Surveillance and characterisation by pulsed-field gel electrophoresis of Cronobacter spp. in farming and domestic environments, food production animals and retail foods. Int J Food Microbiol 136(2):198-203
Mozrová V, Břeňová N, Mrázek J, Lukešová D, Marounek M (2014) Surveillance and characterisation of Cronobacter spp. in Czech retail food and environmental samples. Folia Microbiol 59(1):63-68

Mullane N, Healy B, Meade J, Whyte P, Wall P, Fanning S (2008) Dissemination of Cronobacter spp. (Enterobacter sakazakii) in a powdered milk protein manufacturing facility. Appl Env Microbiol 74(19):5913-5917

Noble JH Jr (2006) Meta-analysis: methods, strengths, weaknesses, and political uses. J Lab Clin Med 147:7-20

O'Brien S, Healy B, Negredo C, Anderson W, Fanning S, Iversen C (2009) Prevalence of Cronobacter species (Enterobacter sakazakii) in follow-on infant formulae and infant drinks. Lett Appl Microbiol 48(5):536-541

Osaili T, Forsythe S (2009) Desiccation resistance and persistence of Cronobacter species in infant formula. Int J Food Microbiol 136:214-220

Pagotto FJ, Farber JM (2009) Cronobacter spp. (Enterobacter sakazakii): advice, policy and research in Canada. Int J of Food Microbiol 136:238-245

Pan Z, Cui JH, Lyu GP, Du XL, Qin LY, Guo YM et al (2014) Isolation and molecular typing of Cronobacter spp. in commercial powdered infant formula and follow-up formula. Foodborne Pathog Dis 11:456-461. doi:10.1089/ fpd.2013.1691

Schmid M, Iversen C, Gontia I, Stephan R, Hofmann A, Hartmann A, Jha B, Eberl L, Riedel K, Lehner A (2009) Evidence for a plant-associated natural habitat for Cronobacter spp. Res Micro 160(8):608-614

Soon JM, Baines R, Seaman P (2012) Meta-analysis of food safety training on hand hygiene knowledge and attitudes among food handlers. J Food Prot 75:793-804

Sutton AJ, Abrams KR, Jones DR (2001) An illustrated guide to the methods of meta-analysis. J Eval Clin Pract 7:135-148

Terragno R, Salve A, Pichel M, Epszteyn S, Brengi S, Binsztein N (2009) Characterization and subtyping of Cronobacter spp. from imported powdered infant formulae in Argentina. Int J Food Microbiol 136(2):193-197

Wang X, Zhu C, Xu X, Zhou G (2012) Real-time PCR with internal amplification control for the detection of Cronobacter spp. (Enterobacter sakazakii) in food samples. Food Control 25:144-149. doi:10.1016/j. foodcont.2011.10.037

Xavier C, Gonzales-Barron U, Paula V, Estevinho L, Cadavez V (2014) Metaanalysis of the incidence of foodborne pathogens in Portuguese meats and their products. Food Res Int 55:311-323

\section{Submit your manuscript to a SpringerOpen ${ }^{\odot}$ journal and benefit from:}

- Convenient online submission

- Rigorous peer review

- Immediate publication on acceptance

- Open access: articles freely available online

- High visibility within the field

- Retaining the copyright to your article

Submit your next manuscript at springeropen.com 